\title{
Polyethylene glycol as a cause of anaphylaxis
}

\author{
Katharina Wylon*, Sabine Dölle and Margitta Worm
}

\begin{abstract}
Background: Polyethylene glycols (PEGs) or macrogols are polyether compounds and are widely used as additives in pharmaceuticals, cosmetics, and food.

Case report: We report on a Caucasian patient experiencing recurrent severe allergic reactions to several drugs. An extensive diagnostic workup including skin prick tests, intradermal tests (IDT) and a double-blind oral challenge was performed to identify the trigger of anaphylaxis. In the present case hypersensitivity to the additive polyethylene glycol was confirmed by an IDT suggesting an Immunoglobulin E-dependent mechanism as a cause of the reaction.

Conclusion: Potential life-threatening hypersensitivity reactions to hidden molecules like macrogol may be underdiagnosed. Cases of immediate-type PEG hypersensitivity were reported with increasing frequency. The awareness regarding the allergenic potential of PEG should be raised and a proper product labelling is crucial to prevent PEG mediated hypersensitivity.
\end{abstract}

Keywords: Anaphylaxis, Drug additives, Hypersensitivity, Macrogol, Polyethylene glycol

\section{Background}

Polyethylene glycol (PEG) or macrogol is a polyether compound. It is widely used as an additive in pharmaceuticals, cosmetics and food [1]. Different types of macrogol exist according to their molecular weight from $300 \mathrm{~g} / \mathrm{mol}$ to $10,000,000 \mathrm{~g} / \mathrm{mol}$ [2]. Anaphylactic reactions to macrogol are rarely reported. However, in recent years more reports appeared in the literature with macrogol induced hypersensitivities due to drugs, personal hygiene products, dental products, lozenges and lubricants [3, 4]. Here we report on a female with a history of three immediate type reactions triggered by macrogol 3350 .

\section{Case report}

A 46-year-old Caucasian female with no known allergies received an intraarticular injection with a local anesthetic $\left(\right.$ Xylonest $^{\circledR}$ : prilocaine, sodium chloride, sodium hydroxide/hydrochloric acid 7\%). Eight hour after the injection she experienced nausea and a generalized pruritus. The symptoms resolved the next day without any

\footnotetext{
*Correspondence: katharina-sophie.wylon@charite.de

Klinik für Dermatologie, Venerologie und Allergologie, Charité

Universitätsmedizin Berlin, Charitéplatz 1, 10117 Berlin, Germany
}

medical treatment. One day later the patient was given an injection with medroxyprogesteronacetate $\left(\right.$ Clinovir $^{\circledR}$ : medroxyprogesteronacetate, methyl-4-hydroxybenzoate and propyl-4-hydroxybenzoate, macrogol 3350, polysorbate 80 , sodium chloride) from her gynecologist. Five minutes after the injection she developed generalized pruritus, sneezing, nausea and tachycardia. Previous injections with medroxyprogesteronacetate and prilocaine were well tolerated.

One year later the patient received an injection to treat a lumbar intervertebral disc prolapse containing lidocaine, bupivacaine hydrochloride, triamcinolone acetonide (Triamhexal ${ }^{\circledR}$ : triamcinolonacetonide, benzyl alcohol, macrogol 4000, sodium chloride, sodium dihydrogen phosphate-dihydrate, sodium hydrogen carbonate, polysorbate 80 ). Within $5 \mathrm{~min}$ the patient developed systemic anaphylactic symptoms, including pruritus, nausea, tachycardia and flush.

The patient presented to our outpatient clinic 4 months after the first incident and 3 days after the third reaction. We initiated an allergological work-up including skin prick tests with macrogol, Clinovir ${ }^{\circledR}$, latex, benzyl alcohol, paraben mix, sodium-benzoate, p-hydroxybenzate acid, sodium-metabisulfite, local anesthetics (procaine 
$1 \%$, lidocaine $1 \%$, bupivacaine $0.5 \%$, prilocaine $1 \%$, articaine $1 \%$, mepivacaine $1 \%$, scandicaine $1 \%$, xylocaine $1 \%$, ultracaine $1 \%$, novocaine $1 \%$ ), glucocorticosteroids (dexamethasone, prednisolone, triamcinolone, methylprednisolone) which were negative for all tested substances (Table 1). A negative control (sodium chloride $0.9 \%$ ) and a positive control (histamine $10 \mathrm{mg} / \mathrm{ml}$ ) were included. Total immunoglobulin E (IgE) was $93.5 \mathrm{kU} / \mathrm{l}$ and tryptase was $1.8 \mu \mathrm{g} / \mathrm{l}$. A double-blind, placebo-controlled oral challenge with the additives which are in the preparations of Clinovir $^{\circledR}$ and Triamhexal ${ }^{\circledR}$ (sodium-benzoate $250 \mathrm{mg}$ and p-hydroxybenzoic acid $250 \mathrm{mg}$ ) was negative (Table 2). An intradermal test was performed with local anesthetics and additives of the suspected trigger substances (1\% macrogol 3350, 10\% macrogol 3350, polysorbate 80 , scandicaine, xylocaine, ultracaine, bupivacaine, prilocaine, novocaine). After injecting 1\% macrogol 3350 intradermal a $6 \mathrm{~mm}$ wheel was seen. 15 min later we carried out a second intradermal test with $10 \%$ macrogol 3350 which showed a $6 \mathrm{~mm}$ wheel diameter (Table 3). Consecutively the patient developed a systemic reaction with generalized pruritus and a generalized urticaria. The wheel diameter enlarged up to $12 \mathrm{~mm}, 5 \mathrm{~min}$ after the application.

Based on the history and the obtained skin test results our patient was diagnosed with an immediate type reaction to macrogol. We suspect that the first severe allergic reaction our patient experienced was not solely induced by prilocaine but another local anesthetic or an unknown additive containing macrogol. We prescribed an emergency kit containing an epinephrine auto-injector, a glucocorticosteroid and an antihistamine. The patient received an allergy pass and was instructed to avoid PEG analogues when taking new, over-the-counter drugs prescription drugs, personal hygiene products, dental products and other potentially PEG containing products.

Two years after the diagnosis of the hypersensitivity to macrogol the patient ingested WICK Medinait ${ }^{\circledR}$ (paracetamol, dextromethorphan hydrobromide, doxylaminsuccinate, sucrose, glycerol, macrogol 6000, sodium citrate, sodium benzoate, potassium sorbate) treating a common cold. Again, she developed dyspnea and a generalized rash.
Table 2 Double-blind oral challenge

\begin{tabular}{ll}
\hline Additives & $\begin{array}{c}\text { Na-benzoate } 250 \mathrm{mg}, \mathrm{p} \text {-hydroxybenzoic acid Negative } \\
250 \mathrm{mg}\end{array}$
\end{tabular}

Table 3 Intradermal test (interpretation after 15 min)

\begin{tabular}{|c|c|c|}
\hline Negative control & $\mathrm{NaCl}$ & $0 \mathrm{~mm}$ \\
\hline Positive control & Histamine & $4 \mathrm{~mm}$ \\
\hline \multirow[t]{3}{*}{ Additives } & Macrogol 3350 1\% & $6 \mathrm{~mm}$ \\
\hline & Macrogol 3350 10\% & $6 \mathrm{~mm}$ \\
\hline & Polysorbate 80 1\% & $0 \mathrm{~mm}$ \\
\hline Local anesthetics & $\begin{array}{l}\text { Scandicaine } 1 \% \text {, xylocaine } 1 \% \text {, } \\
\text { ultracaine } 1 \% \text {, bupivacaine } 0,5 \% \text {, prilocaine } \\
1 \% \text {, novocaine } 1 \%\end{array}$ & $0 \mathrm{~mm}$ \\
\hline
\end{tabular}

Positive test result: wheel diameter $>3 \mathrm{~mm}$

\section{Conclusions}

However, data from the European anaphylaxis-registry with currently 7935 registered anaphylactic cases only three were induced by macrogol. These findings may imply that polyethylene glycol hypersensitivity is potentially life-threatening but probably underdiagnosed as many drugs and food items contain macrogol [4-6]. Handling patients with macrogol hypersensitivity can be challenging because of the extensive allergologic work up, the necessity of the physician's expertise and the limited avoidance options because many drugs, including those used for the treatment of allergic reactions such as antihistamines may contain macrogol as an additive [5]. Therefore, specific product labeling and awareness is required. Patients should be educated about drugs which may contain PEGs, but also other products like lubricants or ultrasound gels. Our case indicated the need for an increased patient and physician awareness to the allergic potential of macrogol.

Concerning the mechanism of anaphylaxis mediated by PEGs different mechanisms have been proposed. Our case supports the assumption of cross-reactivity between PEGs of different molecular weights and polyethylene

Table 1 Skin prick test (interpretation after $15 \mathrm{~min}$ )

\begin{tabular}{|c|c|c|}
\hline Negative control & Sodium chloride $0.9 \%$ & $0 \mathrm{~mm}$ \\
\hline Positive control & Histamine & $4 \mathrm{~mm}$ \\
\hline Local anesthetics & $\begin{array}{l}\text { Procaine } 1 \% \text {, lidocaine } 1 \% \text {, bupivacaine } 0,5 \% \text {, prilocaine } 1 \% \text {, articaine } 1 \% \text {, mepivacaine } 1 \% \text {, scandicaine } 1 \% \text {, xylocaine } \\
1 \% \text {, ultracaine } 1 \% \text {, novocaine } 1 \%\end{array}$ & $0 \mathrm{~mm}$ \\
\hline Glucocorticosteroids & Dexamethasone, prednisolone, triamcinolone, methylprednisolone & $0 \mathrm{~mm}$ \\
\hline Others & $\begin{array}{l}\text { Macrogol } 3350 \text { 1\%, macrogol } 3350 \text { 10\%, Depot Clinovir }{ }^{\circledR} \text {, latex, benzyl alcohol 1\%, paraben mix 16\%, sodium-benzoate } \\
\text { 5\%, p-hydroxybenzate acid, sodium-metabisulfite }\end{array}$ & $0 \mathrm{~mm}$ \\
\hline
\end{tabular}

Positive test result: wheel diameter $>3 \mathrm{~mm}$ 
glycol analogues [7, 8]. Like other authors have previously shown, the positive intradermal test suggests an IgE-dependent mechanism, although no control tests were performed on healthy individuals to rule out unspecific reactivity [9]. However, even after a 1:10 dilution a positive intradermal test was observed. Other methods besides an oral challenge test to confirm the diagnosis may be by basophil activation test or western blot to show specific IgE binding [9].

In conclusion, cases of immediate-type PEG hypersensitivity are reported with increasing frequency, therefore, awareness of PEG's allergenic potential should be raised and better product labeling should be discussed.

\section{Abbreviations}

IgE: immunoglobulin E; IDT: intradermal test; PEG: polyethylene glycol.

\section{Authors' contributions}

$\mathrm{KW}$ collected the data and wrote the manuscript. SD provided and analyzed the data from the anaphylaxis registry. MW coordinated and edited the manuscript. All authors read and approved the final manuscript.

\section{Acknowledgements}

Not applicable.

\section{Competing interests}

The authors declare that they have no competing interests.

\section{Availability of data and materials}

All data is stored and available in the patients case files and may be requested to see a copy at any stage.

\section{Consent for publication}

Written and oral informed consent for publication has been obtained from the patients and stored in the case files and may be requested to see a copy at any stage.
Ethics approval and consent to participate

Written and oral informed consent to participate has been obtained from the patients and stored in the case files and may be requested to see a copy at any stage.

\section{Funding}

The publication fee will be funded by NORA eV (Network for Online-Registration of Anaphylaxis)

Received: 10 June 2016 Accepted: 29 November 2016

Published online: 13 December 2016

\section{References}

1. Pizzimenti S, Heffler E, Gentilcore E, Raie A, Bussolino C, Nebiolo F, et al. Macrogol hypersensitivity reactions during cleansing preparation for colon endoscopy. J Allergy Clin Immunol Pract. 2014;2(3):353-4.

2. Jakasa I, Verberk MM, Esposito M, Bos JD, Kezic S. Altered penetration of polyethylene glycols into uninvolved skin of atopic dermatitis patients. J Invest Dermatol. 2007;127(1):129-34.

3. Bordere A, Stockman A, Boone B, Franki AS, Coppens MJ, Lapeere H, et al. A case of anaphylaxis caused by macrogol 3350 after injection of a corticosteroid. Contact Dermat. 2012;67(6):376-8.

4. Wenande E, Garvey LH. Immediate-type hypersensitivity to polyethylene glycols: a review. Clin Exp Allergy. 2016;46(7):907-22. doi:10.1111/ cea.12760.

5. Hyry H, Vuorio A, Varjonen E, Skytta J, Makinen-Kiljunen S. Two cases of anaphylaxis to macrogol 6000 after ingestion of drug tablets. Allergy. 2006;61(8):1021.

6. Schuman E, Balsam PE. Probable anaphylactic reaction to polyethylene glycol electrolyte lavage solution. Gastrointest Endosc. 1991;37(3):411.

7. Fisher AA. Immediate and delayed allergic contact reactions to polyethylene glycol. Contact Dermat. 1978;4(3):135-8.

8. Yamasuji Y, Higashi Y, Sakanoue M, et al. A case of anaphylaxis caused by polyethylene glycol analogues. Contact Dermat. 2013;69:183-5.

9. Wenande EC, et al. Inhibition of polyethylene glycol-induced histamine release by monomeric ethylene and diethylene glycol: a case of probable polyethylene glycol allergy. Allergy Clin Immunol. 2013;131:1425.

Submit your next manuscript to BioMed Central and we will help you at every step:

- We accept pre-submission inquiries

- Our selector tool helps you to find the most relevant journal

- We provide round the clock customer support

- Convenient online submission

- Thorough peer review

- Inclusion in PubMed and all major indexing services

- Maximum visibility for your research

Submit your manuscript at www.biomedcentral.com/submit 